\title{
Rare Courses of the Mandibular Canal in the Molar Regions of the Human Mandible: A Cadaveric Study
}

\author{
By \\ Iwao SATO ${ }^{1)}$, Ryuji UENO ${ }^{1)}$, Taisuke KAWAI ${ }^{2)}$ and Takashi YOSUE ${ }^{2)}$ \\ ${ }^{1)}$ Department of Anatomy, ${ }^{2)}$ Department of Oral and Maxillofacial Radiology, School of Dentistry at Tokyo, \\ Nippon Dental University, Tokyo, Japan
}

- Received for Publication, August 8, $2005-$

\begin{abstract}
Key Words: Mandibular canal, Course, CT, X-ray
Summary: The inferior alveolar artery, vein and nerve send some branches to the molar teeth via the mandibular canal to the mental foramen. The present study attempted to define the presence and course of the mandibular canal in the mandible with the alveolar process by macroscopic cadaveric dissection and computerized tomography (CT) in order to provide information that might prevent injuries to vessels and nerves at risk during root canal treatment.

We identified the position of the mandibular canal within a $30 \%$ ratio of the distance from inferior border of mandible to the apices of the root for 39 out of 131 sides (mesial root of first molar, $20 \%$; distal root of first molar, $22.6 \%$; mesial root of second molar, $27.8 \%$ and distal root of second molar, $47 \%$ ) on panoramic X-ray observation. In one cadaver (male, 64 years old), the root apex of the second molar was in close proximity to the upper bony mandibular canal. Macroscopic dissection and computerized tomography showed that the main trunks of the inferior alveolar artery, vein, and nerve were in tight contact with the apex of the second molar. These observations of the anatomic course of the mandibular canal will be important to consider during root canal treatment of mandibular teeth.
\end{abstract}

The course of the mandibular canal carrying the inferior alveolar nerve, artery, and vein partly changes as a result of continuous alveolar ridge resorption while teeth are present. Ulm et al. (1993) suggested that the location and course of the mandibular canal remains relatively unchanged in the cranial and caudal border of the mandible except for atrophy at the lingual and buccal external border ${ }^{18)}$. Nortié et al. (1977) suggested that information about variations in branching of the mandibular canal would be useful for prosthodontists and orthodontists when planning treatment ${ }^{15)}$. Yosue et al. (1989) also described the position of the mandibular canal using pantomograms ${ }^{20-21)}$. However, data obtained by panoramic radiography are useful only when the mandibular canal is located high and low and superior-inferiorly, and therefore more detailed observation is necessary. Anderson et al. (1991) suggested the presence of various nerve plexuses in the mandibular canal ${ }^{1)}$. Littner et al. (1986) stated that data on the position of the mandibular canal in the area between the root apices of the molars and an extracted third molar is useful for surgical and endodontic procedures ${ }^{13)}$. It has been reported that the position of the inferior alveolar nerve, in terms of anatomical location, course and arrangement, should be given more attention when planning dental implant treatment $^{2,3,6,11)}$. After extraction of a third molar, there is a risk of damage to the inferior alveolar nerve (Renton et al., 2005) ${ }^{17}$. This has also been confirmed by studies involving dissection of the mandible ${ }^{6,14)}$ and CT methods ${ }^{1-12)}$ before endodontic surgery ${ }^{19}$.

In the present study using $\mathrm{CT}$, panoramic $\mathrm{X}$ ray and dissection of Japanese cadavers, we investigated the anatomical structures in the molar region of the human mandible and the course of the mandibular canal, focusing on anatomic peculiarities of the mandibular canal that might be relevant to endodontic procedures involving root canal treatment. 


\section{Materials and Methods}

A total of 75 mandibles from adult Japanese cadavers donated for human dissection at Nippon Dental University were used. A panoramic X-ray machine (Lapix7007, Asahi Roentogen Industry Co. Ltd., Kyoto, Japan; tube potential $70 \mathrm{kV}$; tube current $7 \mathrm{~mA}$; total filtration $2.5 \mathrm{~mm} \mathrm{Al}$; focal spot $0.8 \mathrm{~mm} \times 0.8 \mathrm{~mm}$; time $6 \mathrm{~s}$ ) was employed for plain film imaging of the mandible. Three-dimensional images of the mandible were obtained by reconstruction of CT images using a CT apparatus (Toshiba Medical Co. Ltd., Tokyo, Japan, 120 kV; $50 \mathrm{~mA}$; slice $1 \mathrm{~mm}$; table speed $0.75 \mathrm{~s} / \mathrm{mm}$ ). The mandibular canal was observed in the molar region. We removed pieces of cortical bone and bone tissue from the molar region of the mandible by piecemeal osteotomy guided by CT images and Xray photography, paying careful attention to avoid damaging the mandibular canal. After removal of the bone, we identified the arrangement of each molar tooth root in the posterior region of the mandible.

\section{Results}

\section{Panoramic X-ray of the mandibular canal}

We measured four points: a, the distance between the lower border of the mandibular canal and the inferior border of the mandible; $b$, the vertical diameter of the mandibular canal; c, the distance from the upper border of the mandibular canal to the apex of the tooth root; $\mathrm{d}$, the distance from the inferior border of the mandible to the apex of the tooth root (Fig. 1, Tables 1-3). Panoramic X-ray observation revealed the significant

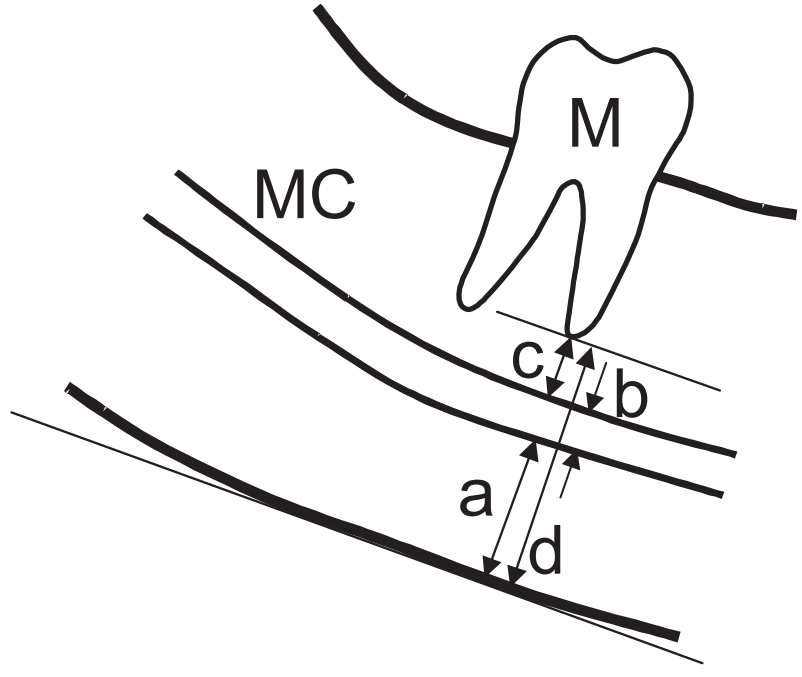

Fig. 1. Schematic diagram of the measurement at the mandibular molar region.

M, molar; MC, mandibular canal.

a, the distance between the lower border of the mandibular canal and the inferior border of the mandible; $\mathbf{b}$, the vertical diameter of the mandibular canal; c, the distance from the upper border of the mandibular canal to the apex of the tooth root; d, the distance from the inferior border of the mandible to the apex of the tooth root.

presence of the mandibular canal in the region of the first and second molars in the posterior part of the mandible. We identified the position of the mandibular canal within a $30 \%$ ratio of the distance from inferior border of mandible to the apices of the root for 39 out of 131 sides (mesial root of first molar, $20 \%$; distal root of first molar, $22.6 \%$; mesial root of second molar, $27.8 \%$ and distal root of sec-

Table 1. Dimension of the madibular molar region near the first molar tooth in human

\begin{tabular}{|c|c|c|c|c|c|c|}
\hline \multirow[t]{2}{*}{ Position } & & \multicolumn{2}{|c|}{ Male } & \multicolumn{2}{|c|}{ Female } & \multirow[t]{2}{*}{ Total } \\
\hline & & $\mathrm{R}$ & $\mathrm{L}$ & $\mathrm{R}$ & $\mathrm{L}$ & \\
\hline \multirow[t]{2}{*}{$\mathrm{a}$} & 1 & $0.93 \pm 0.19$ & $1.03 \pm 0.26$ & $0.92 \pm 0.45$ & $0.91 \pm 0.18$ & $0.96 \pm 0.26$ \\
\hline & 2 & $0.89 \pm 0.18$ & $1.03 \pm 0.27$ & $0.90 \pm 0.36$ & $0.86 \pm 0.13$ & $0.94 \pm 0.24$ \\
\hline \multirow[t]{2}{*}{ b } & 1 & $0.43 \pm 0.06$ & $0.47 \pm 0.14$ & $0.50 \pm 0.19$ & $0.52 \pm 0.20$ & $0.48 \pm 0.15$ \\
\hline & 2 & $0.51 \pm 0.14$ & $0.48 \pm 0.14$ & $0.55 \pm 0.19$ & $0.47 \pm 0.16$ & $0.49 \pm 0.15$ \\
\hline \multirow[t]{2}{*}{$\mathrm{c}$} & 1 & $1.07 \pm 0.52$ & $1.20 \pm 0.61$ & $0.88 \pm 0.47$ & $1.03 \pm 0.32$ & $1.06 \pm 0.49$ \\
\hline & 2 & $1.06 \pm 0.50$ & $1.08 \pm 0.60$ & $0.73 \pm 0.34$ & $0.97 \pm 0.25$ & $0.99 \pm 0.47$ \\
\hline \multirow[t]{2}{*}{ d } & 1 & $2.56 \pm 0.62$ & $2.72 \pm 0.64$ & $2.34 \pm 0.18$ & $2.46 \pm 0.28$ & $2.55 \pm 0.50$ \\
\hline & 2 & $2.52 \pm 0.62$ & $2.58 \pm 0.65$ & $2.24 \pm 0.28$ & $\begin{array}{l}2.30 \pm 0.25 \\
(\mathrm{n}=5-13)\end{array}$ & $\begin{array}{l}2.43 \pm 0.51 \\
(\mathrm{n}=29-32)\end{array}$ \\
\hline
\end{tabular}

a, the distance between the lower border of the mandibular canal and the inferior border of the mandibule; $b$, the vertical diameter of the mandibular canal; $\mathrm{c}$, the distance from the upper border of the mandibular canal to the apex of the tooth root; d, the distance from the inferior border of the mandible to the apex of the tooth root. 
Table 2. Dimension of the madibular molar region near the second molar tooth in human

\begin{tabular}{|c|c|c|c|c|c|c|}
\hline \multicolumn{2}{|c|}{ Position } & \multicolumn{2}{|c|}{ Male } & \multicolumn{2}{|c|}{ Female } & \multirow[t]{2}{*}{ Total } \\
\hline & & $\mathrm{R}$ & $\mathrm{L}$ & $\mathrm{R}$ & $\mathrm{L}$ & \\
\hline \multirow[t]{2}{*}{$\mathrm{a}$} & 1 & $1.02 \pm 0.33$ & $1.06 \pm 0.28$ & $0.91 \pm 0.35$ & $0.91 \pm 0.16$ & $0.98 \pm 0.28$ \\
\hline & 2 & $1.10 \pm 0.36$ & $1.15 \pm 0.28$ & $0.94 \pm 0.33$ & $0.99 \pm 0.20$ & $1.06 \pm 0.30$ \\
\hline \multirow[t]{2}{*}{$\mathrm{b}$} & 1 & $0.47 \pm 0.12$ & $0.50 \pm 0.10$ & $0.54 \pm 0.16$ & $0.48 \pm 0.17$ & $0.49 \pm 0.13$ \\
\hline & 2 & $0.54 \pm 0.19$ & $0.48 \pm 0.13$ & $0.45 \pm 0.24$ & $0.42 \pm 0.24$ & $0.48 \pm 0.20$ \\
\hline \multirow[t]{2}{*}{$\mathrm{c}$} & 1 & $0.95 \pm 0.42$ & $0.90 \pm 0.55$ & $0.56 \pm 0.33$ & $0.68 \pm 0.40$ & $0.79 \pm 0.44$ \\
\hline & 2 & $0.83 \pm 0.42$ & $0.81 \pm 0.63$ & $0.49 \pm 0.24$ & $0.57 \pm 0.37$ & $0.70 \pm 0.45$ \\
\hline \multirow[t]{2}{*}{ d } & 1 & $2.43 \pm 0.51$ & $2.46 \pm 0.72$ & $2.01 \pm 0.27$ & $2.06 \pm 0.48$ & $2.27 \pm 0.55$ \\
\hline & 2 & $2.47 \pm 0.50$ & $2.44 \pm 0.82$ & $1.96 \pm 0.25$ & $\begin{array}{l}2.03 \pm 0.55 \\
(\mathrm{n}=6-11)\end{array}$ & $\begin{array}{l}2.27 \pm 0.60 \\
(\mathrm{n}=34-36)\end{array}$ \\
\hline
\end{tabular}

a, the distance between the lower border of the mandibular canal and the inferior border of the mandibule; $b$, the vertical diameter of the mandibular canal; $\mathrm{c}$, the distance from the upper border of the mandibular canal to the apex of the tooth root; d, the distance from the inferior border of the mandible to the apex of the tooth root.

Table 3. The percentage of the position of the mandibular canal within a $30 \%$ ratio of the distance from inferior border of mandible to the apices of the root

\begin{tabular}{|c|c|c|c|c|c|c|c|}
\hline \multirow[t]{2}{*}{ Position } & \multicolumn{3}{|c|}{ Male } & \multicolumn{3}{|c|}{ Female } & \multirow[t]{2}{*}{ Total } \\
\hline & $\mathrm{R}$ & $\mathrm{L}$ & $\mathrm{R}+\mathrm{L}$ & $\mathrm{R}$ & $\mathrm{L}$ & $\mathrm{R}+\mathrm{L}$ & \\
\hline $\begin{array}{l}\text { Mesial root of } \\
\text { first molar }\end{array}$ & 33.3 & 10.0 & 18.8 & 16.7 & 25.0 & 21.4 & 20.0 \\
\hline $\begin{array}{l}\text { Distal root of } \\
\text { first molar }\end{array}$ & 42.9 & 18.2 & 27.8 & 40.0 & 0.00 & 15.3 & 22.6 \\
\hline $\begin{array}{l}\text { Mesial root of } \\
\text { second molar }\end{array}$ & 9.1 & 33.3 & 20.0 & 42.9 & 33.3 & 37.5 & 27.8 \\
\hline $\begin{array}{l}\text { Distal root of } \\
\text { second molar }\end{array}$ & 9.1 & 66.6 & 35.0 & 83.0 & 50.0 & 64.2 & 47.0 \\
\hline
\end{tabular}

ond molar, 47\%) on panoramic X-ray observation. The distance from the upper border of the mandibular canal to the apex of the tooth root in first molar was shorter than that of second molar tooth. The vertical diameter of the mandibular canal was about $0.48 \mathrm{~mm}$. The position of mandible canal was about $10 \mathrm{~mm}$ from the inferior border of the mandible to lower border of mandibular canal. The distance from the upper border of the mandibular canal to the apex of the first molar tooth root was larger than that of second molar however no exceeded $10 \mathrm{~mm}$ in the examined samples, and the distance between the lower border of the mandibular canal and the inferior border of the mandible was within $25 \mathrm{~mm}$. The distance from the inferior border of the mandible to the apex of the tooth root was greater in samples from males than in samples from females. The vertical diameter of the mandibular canal in samples from males was about $5 \mathrm{~mm}$, being similar to that in samples from females (Fig. 2).

\section{Close proximity of the mandibular canal to the} apices of the molar teeth

In one case (male, 64 years old) the mandibular canal ran directly underneath the apices of the molars in the posterior region of the mandible; however, no branches of the mandibular canal could be clearly identified. CT and panoramic X-ray images showed that the tooth root was closely bound on the mandibular canal on the right side of the mandible (Figs. 3, 4). A series of cross-sectional CT images showed that the mandibular canal had small ridges appearing as radiopaque lines extending from the posterior to anterior region of the premolars (Fig. 5).

\section{Discussion}

The course of the mandibular canal runs from the mandibular foramen toward the mental foramen, and has been classified by previous reports based on radiographic observations ${ }^{5,7,10,15)}$. However, the mandibular canal in relation to surrounding bone structures is difficult to visualize by radiography, and computer-assisted systems are required to clarify the course and arrangement of the mandibular canal in the molar region. The anatomical condition of the molar region can yield information that is beneficial for implant placement, and also for reconstruction of the mandible from CT images. In our study, CT images gave useful information about the bone structure and distance 


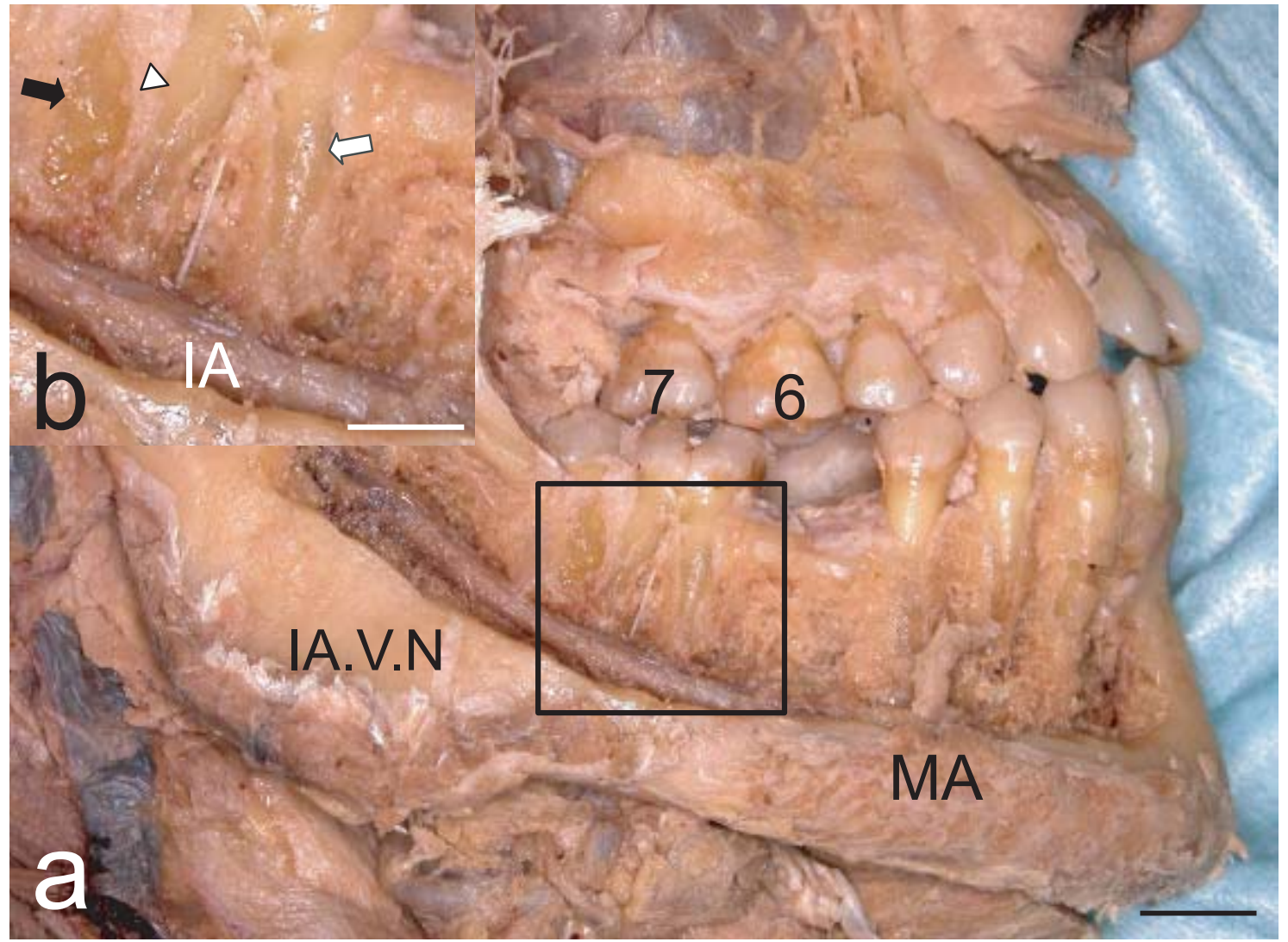

Fig. 2. Lateral view of the right molar region of mandible in human cadaver (male, 64 years old).

a, The position of the root of second and third right molar tooth in mandible of human cadaver.

IA.V.N, inferior alveolar artery, vein and nerve; MA, mental artery. 6, maxillary right first molar; 7, maxillary right second molar. bar $=5 \mathrm{~mm}$.

b, Large magnified figure of the root of molar region in mandible surrounded by a black border.

IA, Inferior alveolar artery. White arrow, mesial root of mandibular right second molar; white arrowhead, distal root of mandibular right second molar; black arrow, medial root of mandibular right third molar. bar $=10 \mathrm{~mm}$.

between the mandibular canal and molar roots, which would be useful for indicating the possible risks of vessel and nerve injury in the molar region during root canal treatment. Gowgiel (1992) reported that the course and position of the mandibular canal varied slightly in the molar region on the lingual cortical palate side ${ }^{9}$. Rajchel (1986) reported that the course of the mandibular canal ran laterally on the buccal side ${ }^{16)}$. Littner et al. (1986) suggested that the mandibular canal was located buccal to the apex of the second molar in the majority of cases, and lingual to the apex of the first molar in almost half of all cases ${ }^{13}$. These studies indicated that the course of the mandibular canal in the buccal and lingual directions was affected by the presence of teeth in the molar region of the mandible. Resorption of the alveolar bone during aging affects the location of the mandibular canal. In our study we measured the position of the mandibular canal in terms of the height between the inferior border of the mandible and the tooth root. Frankle et al. (1990) reported that the vertical distance of the position of the anatomical apex of the mesial roots was significantly less for the second molar than for the first molar ${ }^{8)}$. Bell (2004) indicated an important relationship between the third molar and the inferior alveolar nerve ${ }^{4)}$. Therefore, the vertical distance between the tooth root and the mandibular canal is an important factor that has to be considered in dental treatment. The position of the mandibular canal within a $30 \%$ ratio of the distance from inferior border of mandible to the apices of the root was $29.8 \%$ in our examined cases. These findings suggest that there are sometimes inherent anatomical risks of orthodontic treatment. In one case we examined, the mandibular canal ran di- 


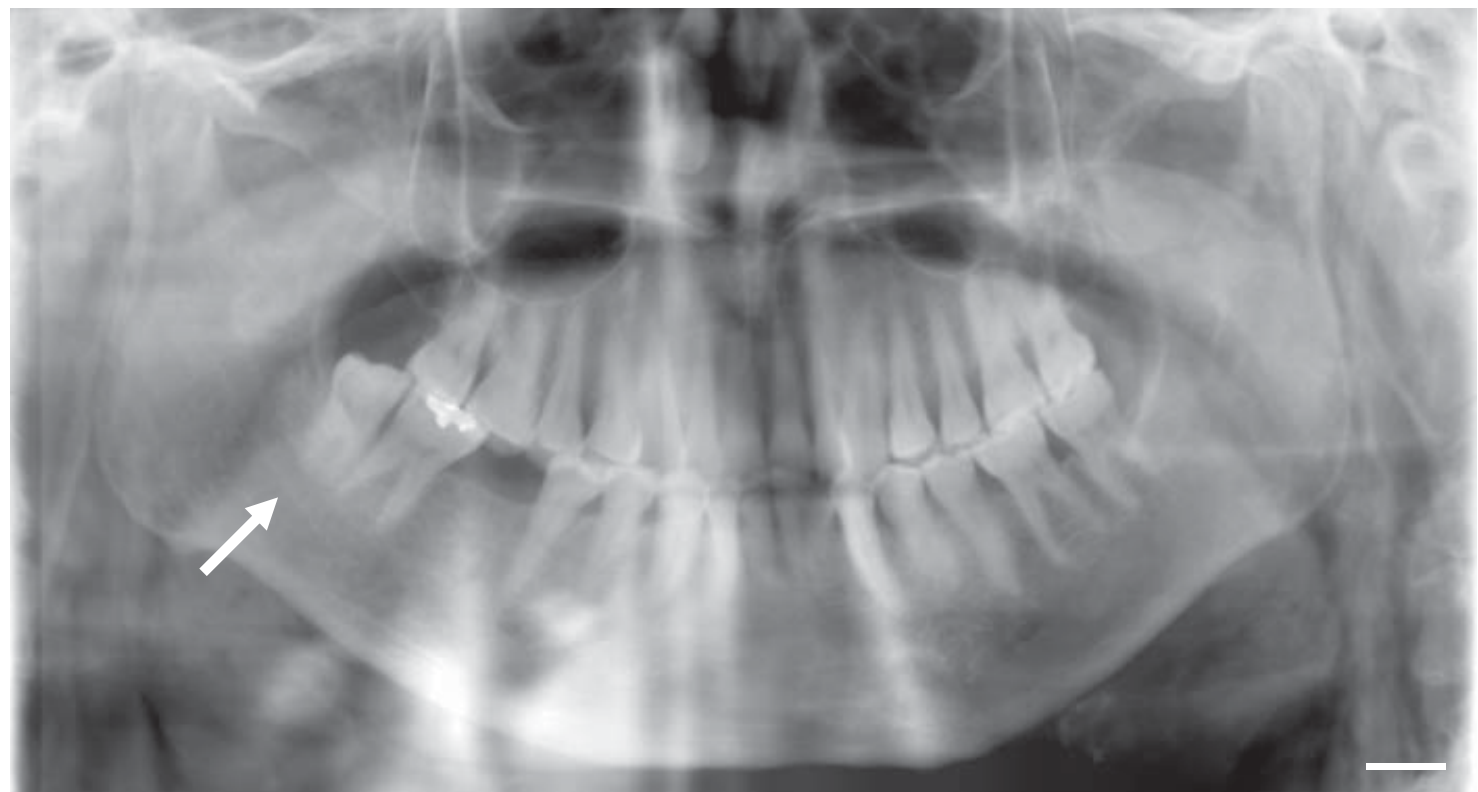

Fig. 3. Panoramic X-ray observation of mandible from one cadaver (see Fig. 2) (male, 64 years old). The mandibular canal identified because of its orientation in the molar region (arrow). bar $=10 \mathrm{~mm}$.

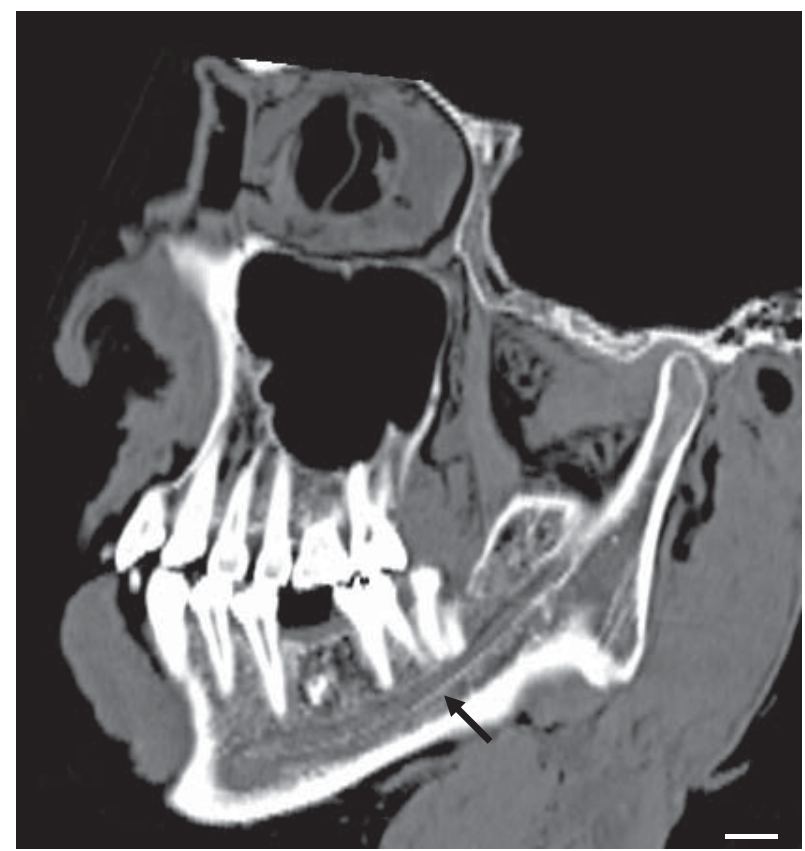

Fig. 4. Three dimensional CT images of mandible from one cadaver (right side, male, 64 years old). Sagittal sectional view from $\mathrm{CT}$ scan from continuity 36 slices of mandible in Fig. 2. bar $=10 \mathrm{~mm}$. rectly underneath the tooth apices in the molar region of the mandible. Ulm et al. (1993) suggested that the distance between the mandibular canal and the lingual and buccal external border did not change at any stage of the atrophic process ${ }^{18)}$. Rajchel et al. (1986) also indicated that the mandibular canal was thick at its lowest points near the distal half of the first molar and mandibular body and buccal cortical plate ${ }^{16}$. Therefore this single Japanese case was considered to represent a rare arrangement and location of the mandibular canal.

\section{References}

1) Anderson LC, Kosinshi TF and Mentag PJ. A review of the intraosseous course of the nerves of the mandible. J Oral Implantol 1991; 17:394-403.

2) Arzouman MJ, Otis L, Kipnis $\mathrm{V}$ and Levine D. Observations of the anterior loop of the inferior alveolar canal. Int J Oral Maxillofac Implants 1993; 8:295-300.

3) Bavitz JB, Harn SD, Hansen CA and Lang M. An anatomical study of mental neurovascular bundle-implant relationships. Int J Oral Maxillofac Implants 1993; 8:563567.

4) Bell GW. Use of dental panoramic tomographs to predict the relation between mandibular third molar teeth and the inferior alveolar nerve. Radiological and surgical findings, and clinical outcome. Br J Oral Maxillofac Surg 2004; 42:21-27.

5) Carter RB and Kee EN. The intramandibular course of the inferior alveolar nerve. J Anat 1971; 108:433-440. 


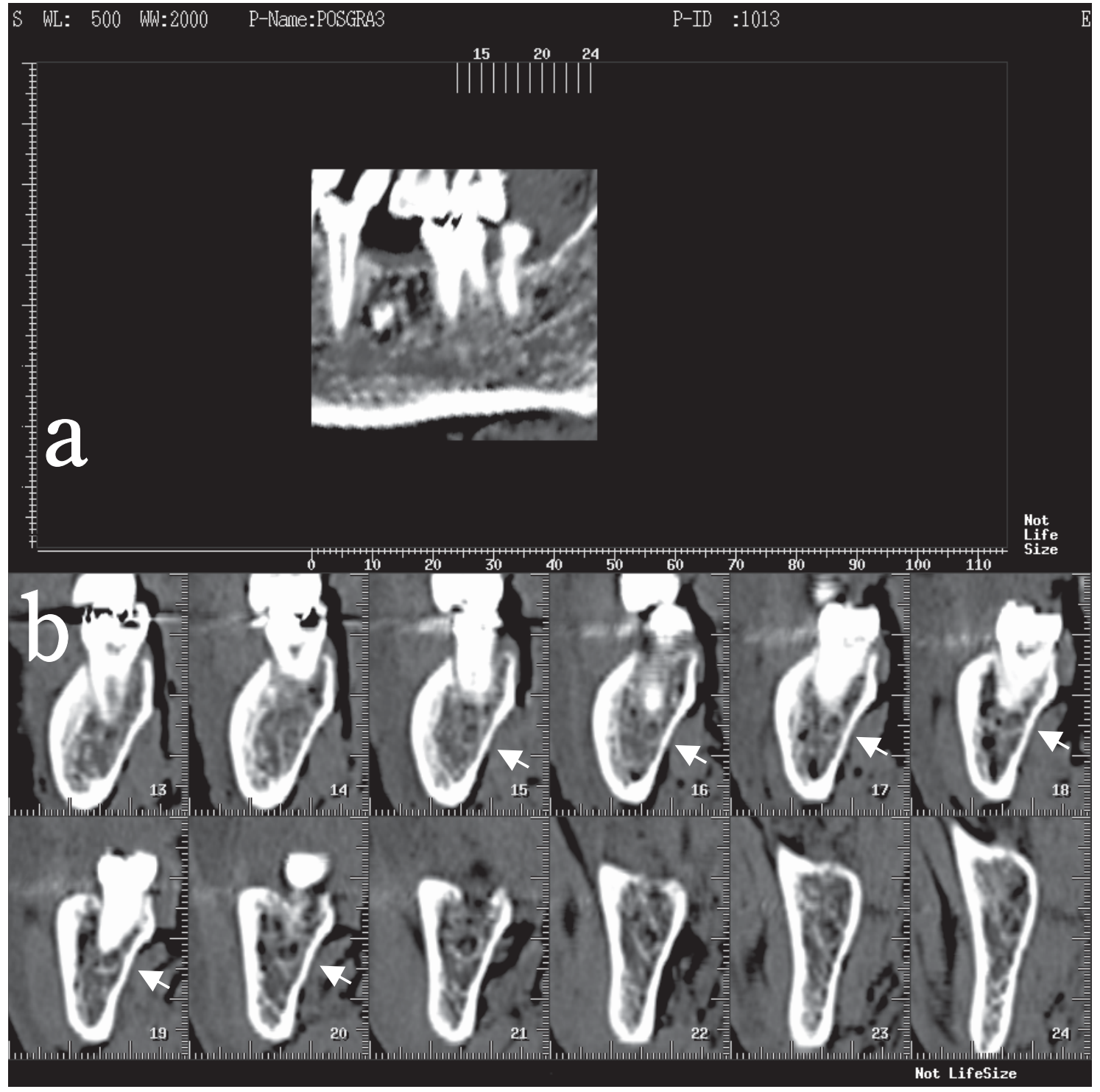

Fig. 5. CT image from continuity 12 slices of mandibular molar region in the cadaver (right side, male, 64 years old).

From series of cross-sectional CT images the lingual canal (arrows) was seen below the root of the second molar tooth. a, reconstruction CT images from 12 slices of mandibular region; $\mathbf{b}, 12$ slices of mandible.

6) De Andrade E, Otomo-Corgel J, Pucher J, Ranganath KA $\mathrm{Jr}$ and St George N. The intraosseous course of the mandibular incisive nerve in the mandibular symphysis. Int $\mathrm{J}$ Periodontics Restorative Dent 2001; 21:591-597.

7) Fox NA. The position of the inferior dental canal and its relation to the mandibular second molar, Br Dent J 1989; 167:19-21.

8) Frankle KT, Seibel W and Dumsha TC, Anatomical study of the position of the mesial roots of mandibular molars. $\mathrm{J}$ Endod 1990; 16:480-485.

9) Gowgiel JM. The position and course of the mandibular canal. J Oral Implantol 1992; 18:383-385.

10) Heasman PA. Variation in the position of the inferior dental canal and its significance to restorative dentistry. J Dent 1988; 16:36-39.
11) Jacobs R, Mraiwa N, van Steenberghe D, Gijbels F and Mirynen M. Appearance, location, course, and morphology of the mandibular incisive canal: an assessment on spiral CT scan. Dentomaxillofac Radiol 2002; 31:322-327.

12) Kondo T, Ong $\mathrm{SH}$ and Foong KW. Computer-based extraction of the inferior alveolar nerve canal in 3-D space. Comput Methods Programs Biomed 2004; 76:181-191.

13) Littner MM, Kaffe I, Tamse A and Dicapua P. Relationship between the apices of the lower molars and mandibular canal - a radiographic study. Oral Surg Oral Med Oral Pathol 1986; 62:595-602.

14) Mraiwa N, Jacobs R, van Steenberghe D and Quirynen M. Clinical assessment and surgical implications of anatomic challenges in the anterior mandible. Clin Implant Dent Relat Res 2003; 5:219-225. 
15) Nortjé CJ, Farman AG and de V Joubert JJ. The radiographic appearance of the inferior dental canal: an additional variation. Br J Oral Surg 1977; 15:171-172.

16) Rajchel J, Ellis E $3^{\text {rd }}$ and Fonseca RJ. The anatomical location of the mandibular canal: its relationship to the sagittal ramus osteotomy. Int $\mathbf{J}$ Adult Orthodon Orthognath Surg 1986; 1:37-47.

17) Renton T, Hankins $M$, Sproate $C$ and McGurk M. A randomised controlled clinical trial to compare the incidence of injury to the inferior alveolar nerve as a result of coronectomy and removal of mandibular third molars. Br J Oral Maxillofac Surg 2005; 43:7-12.

18) Ulm CW, Solar P, Blahout R, Matejka M, Watzek G and
Gruber H. Location of the mandibular canal within the atrophic mandible. Br J Oral Maxillofac Surg 1993; 31:370-375.

19) Velvart P, Hecker $H$ and Tillinger G. Detection of the apical lesion and the mandibular canal in conventional radiography and computed tomography. Oral Surg Oral Med Oral Pathol Oral Radiol Endod 2001 Dec; 92(6):682-688.

20) Yosue $T$ and Brooks SL. The appearance of mental foramina on panoramic radiographs. I. Evaluation of patients. Oral Surg Oral Med Oral Pathol 1989; 68:360-364.

21) Yosue $T$ and Brooks SL. The appearance of mental foramina on panoramic and periapical radiographs. II. Experimental evaluation. Oral Surg Oral Med Oral Pathol 1989; 68:488-492. 